\title{
Serotype diversity as a drawback in the surveillance of Shiga toxin-producing Escherichia coli infections in Brazil
}

Shiga toxin-producing Escherichia coli (STEC) strains have emerged worldwide as an important cause of gastrointestinal diseases and complications in humans (Nataro \& Kaper, 1998). Diarrhoea and haemolytic uraemic syndrome (HUS) associated with STEC have also been reported in patients with acquired immunodeficiency syndrome (AIDS) (Garcia Lara et al., 2000; Suthienkul et al., 2001; Pouessel et al., 2004). Although O157: H7 is the prominent STEC serotype, in the last decade many non-O157 STEC strains were also reported in diarrhoea-associated illnesses and complications. Some outbreaks caused by non-O157 STEC strains have already been reported, although in many countries these organisms are more frequently associated with sporadic cases of diarrhoea, haemorrhagic colitis and HUS (Brooks et al., 2004; Pradel et al., 2000).

In Brazil, human STEC infections have been mainly associated with cases of diarrhoea, especially in children (Guth et al., 2002, 2005; Irino et al., 2002; Vaz et al., 2004). Except for the study of Vaz et al. (2004), which described the identification of one O157 : H7 STEC strain isolated from an human immunodeficiency virus-infected (HIV) patient in the late 1990s, there are no other reports on STEC infection in patients with AIDS in Brazil. A predominance of O111 and O26 serotypes have been reported among STEC strains identified in São Paulo from 1976 through 1999 (Vaz et al., 2004), but continuous surveillance on the occurrence of STEC serotypes as agents of gastrointestinal infection has important implications for diagnostic procedures and the establishment of control measures. This report addresses the importance of not using serotyping alone as a predictor for the presence of STEC.

A total of 439 patients, comprising 337 children and 102 HIV adult patients with diarrhoea, were investigated for the presence of STEC in the western region of São Paulo State in 2000-2003. Stool samples from HIV patients were sent from six public centres for AIDS treatment, and $97.3 \%$ of faecal samples from children were from one private paediatric hospital. A total of 2115 sorbitol-positive and -negative $E$. coli colonies were screened for STEC by colony hybridization assays with specific DNA probes for $s t x_{1}$ and $s t x_{2}$ (Vaz et al., 2004). STEC isolates were biochemically characterized as E. coli, and serotyped by standard methods (Ewing, 1986). STEC strains were identified in 5 of the 337 children $(1.5 \%)$ aged $0-5$, and in 3 of the 102 HIV adult patients (2.9\%), but these differences were not statistically significant. The phenotypic and genotypic characteristics of the STEC strains are shown in the Table 1. The biochemical reactions presented by the STEC strains are in agreement with other studies which reported that only O157: H7 was sorbitolnegative, while failure to decarboxylate lysine occurred only in O111 STEC strains (Farmer \& Davis, 1985; Vaz et al., 2004). A diversity of serotypes was identified among the eight STEC strains isolated. Serotype O77: H18, and untypable serotypes ONT : H2 (two strains) and ONT: H8 were described, for what is believed to be the first time, as being associated with human infections in Brazil. Nevertheless, serotypes O103: H2, O111:NM (non-motile), $\mathrm{O} 118: \mathrm{H} 16$ and $\mathrm{O} 157: \mathrm{H} 7$ were also

Table 1. Diversity of serotypes and virulence characteristics among STEC strains associated with human infections in Brazil in 2000-2003

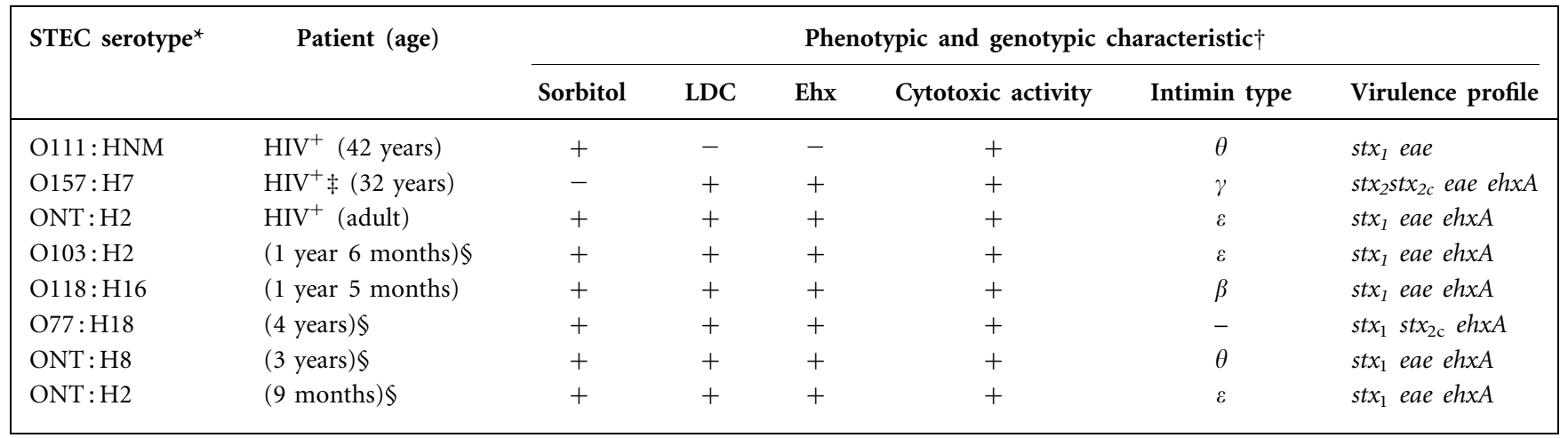

${ }^{*} \mathrm{NM}$, Non-motile; NT, non-typable.

$\nmid$ Sorbitol, fermentation of sorbitol; LDC, lysine decarboxylase; Ehx, production of enterohaemolysin.

$\ddagger$ Bloody diarrhoea.

\$ospitalized with diarrhoea. 
recovered from children and HIV patients, which suggests their possible persistence and circulation in our settings over time. Broad ranges of isolation of $\mathrm{O} 157: \mathrm{H} 7$ strains from HIV patients have been reported in other countries and geographical areas (Suthienkul et al., 2001; Gwavava et al., 2001). In contrast to previous data, which showed that $69 \%$ of the STEC strains isolated from children with diarrhoea in São Paulo from 1976 through 1999 belonged to serotype O111: H8 and O111: NM (Vaz et al., 2004), in the present study these serotypes were only identified once from an HIV patient (Table 1). All STEC isolates presented cytotoxin activity, and except for the $\mathrm{O} 111$ strain all the others produced enterohaemolysin, which were identified as described elsewhere (Vaz et al., 2004). The stx genotypes determined by RFLP-PCR (Cergole- Novella et al., 2006) showed that except for the O157: H7 strain that carried $s t x_{2} s t x_{2 c}$, the other strains harboured only $s t x_{1}$, and one strain carried both $s t x_{1} s t x_{2 c}$ sequences. In addition, the intimin gene (eae) and the plasmidencoding enterohaemolysin gene $(e h x A)$ detected by PCR assays as described by Gannon et al. (1993) and Schmidt et al. (1995), respectively, were carried by most (7 of $8 ; 87.5 \%$ ) of the strains (Table 1 ), with four intimin types being identified (Oswald et al., 2000). Even though the majority of the STEC strains isolated in this study exhibited characteristics of enterohaemorrhagic E. coli (EHEC), only the patient from whom the O157: H7 strain was isolated presented bloody diarrhoea, whereas others had non-bloody diarrhoea without complications.

In conclusion, these data demonstrate the occurrence of important STEC serotypes in children and HIV patients with diarrhoea in Brazil, and confirm previous observations (Vaz et al., 2004; Guth et al., 2005) that non-O157 strains are more frequently associated with human infection than the O157 : H7 serotype, which may have significant implications for the diagnostic procedures employed in clinical laboratories in Brazil. As the importance of these serotypes varies with geographical region, the search for STEC should rely on the detection of stx genes, rather than testing only for specific serotypes of the classical EHEC strains. Otherwise, four of the eight (50\%) STEC strains currently identified would be missed.

\section{Acknowledgements}

This study was supported by grants from Fundação de Amparo à Pesquisa do Estado de São Paulo (FAPESP) no. 01/07921-7, and the Conselho Nacional de Desenvolvimento Científico e Tecnológico, CNPq, Brasília, Brazil. We gratefully acknowledge the assistance of M. R. Poletto, R. Abduch, I. I. Ramos and M. C. Cergole-Novella for technical assistance. The experiments conducted were in accordance with the ethics committee of Universidade Federal de São Paulo - Escola Paulista de Medicina.

\section{Kinue Irino, ${ }^{1}$ Tânia M. I. Vaz,, \\ Marta I. C. Medeiros, ${ }^{3}$ Maria Aidê M. F. Kato, ${ }^{1}$ Tânia A. T. Gomes, ${ }^{2}$ Mônica A. M. Vieira ${ }^{2}$ and Beatriz E. C. Guth ${ }^{2}$ \\ ${ }^{1}$ Seção de Bacteriologia, Instituto Adolfo Lutz, São Paulo, Brazil \\ ${ }^{2}$ Departamento de Microbiologia, Imunologia e Parasitologia, Universidade Federal de São Paulo - Escola Paulista de Medicina, Rua Botucatu 862, São Paulo, CEP 04023-062, São Paulo, Brazil \\ ${ }^{3}$ Instituto Adolfo Lutz, Ribeirão Preto, São Paulo, Brazil}

\section{Correspondence: Beatriz E. C. Guth (becguth@ecb.epm.br)}

Brooks, J. T., Bergmire-Sweat, D., Kennedy, M., Henricks, K., Garcia, M., Marengo, L., Wells, J., Ying, M., Bibb, W. \& other authors (2004). Outbreak of Shiga toxin-producing Escherichia coli $\mathrm{O} 111$ : H8 infections among attendees of a high school cheerleading camp. Clin Infect Dis 38, 190-198.

Cergole-Novella, M. C., Nishimura, L. S., Irino, K., Vaz, T. M. I., Castro, A. F. P., Leomil, L. \& Guth, B. E. C. (2006). Stx genotypes and antimicrobial resistance profiles of Shiga toxin-producing Escherichia coli strains isolated from human infections, cattle and foods in Brazil. FEMS Microbiol Lett 259, 234-239.

Ewing, W. H. (1986). Edwards \& Ewing's Identification of Enterobacteriaceae, 4th edn. New York: Elsevier.

Farmer, J. J., III \& Davis, B. R. (1985). H7 antiserum-sorbitol fermentation medium: a single-tube screening method for detecting Escherichia coli $157: \mathrm{H} 7$ associated with hemorrhagic colitis. J Clin Microbiol 22, 620-625.
Gannon, V. P. J., Rashed, M., King, R. K. \& Thomas, E. J. G. (1993). Detection and characterization of the eae gene of Shiga-like toxin-producing Escherichia coli using polymerase chain reaction. J Clin Microbiol 31, 1268-1274.

Garcia Lara, F. J., Martinez, P. \& Cuadros Gonzales, J. A. (2000). Escherichia coli O157:H7 and hemolytic uremic syndrome in an HIV positive patient. Rev Esp Enferm Dig 92, 820-821.

Guth, B. E. C., Ramos, S. R. T. S., Cerqueira, A. M. F., Andrade, J. R. C. \& Gomes, T. A. T. (2002). Phenotypic and genotypic characteristics of Shiga toxin-producing Escherichia coli strains isolated from children in São Paulo, Brazil. Mem Inst Oswaldo Cruz 97, 1085-1089.

Guth, B. E. C., Vaz, T. M. I., Gomes, T. A. T., Chinarelli, S. H., Rocha, M. M. M., Castro, A. F. P. \& Irino, K. (2005). Re-emergence of O103: H2 Shiga toxin-producing Escherichia coli infections in São Paulo, Brazil. J Med Microbiol 54, 805-806.

Gwavava, C., Chihota, V. N., Gangaidzo, I. T. \& Gumbo, T. (2001). Dysentery in patients infected with human immunodeficiency virus in Zimbabwe: an emerging role for Shistosoma mansoni and Escherichia coli O157. Ann Trop Med Parasitol 95, 509-513.

Irino, K., Vaz, T. M. I., Kato, M. A. M. F., Naves, Z. V. F., Lara, R. R., Marco, M. E. C., Rocha, M. M. M., Moreira, T. P., Gomes, T. A. T. \& Guth, B. E. C. (2002). O157: H7 Shiga toxin-producing Escherichia coli strains associated with sporadic cases of diarrhea in São Paulo, Brazil. Emerg Infect Dis 8, 446-447.

Nataro, J. P. \& Kaper, J. B. (1998).

Diarrheagenic Escherichia coli. Clin Microbiol Rev 11, 142-201.

Oswald, E., Schmidt, H., Morabito, S., Karch, H. Marches, O. \& Caprioli, A. (2000). Typing of intimin genes in human and animal enterohemorrhagic and enteropathogenic Escherichia coli: characterization of a new intimin variant. Infect Immun 68, 64-71.

Pouessel, G., Lahoche, A., Copin, M. C., Ythier, H., Maziangue, F. \& Foulard, F. (2004). Verocytotoxin positive haemolytic uremic syndrome and HIV-associated nephropathy. Nephrologie 25, 141-144.

Pradel, N., Livrelli, V., Champs, C., Palcoux, J. B., Reynaud, A., Scheutz, F., Sirot, F. J., Joly, B. \& Forestier, C. (2000). Prevalence and characterization of Shiga toxin-producing Escherichia coli isolated from cattle, food, and children during a one-year prospective study in France. J Clin Microbiol 38, 1023-1031.

Schmidt, H., Beutin, L. \& Karch, H. (1995). Molecular analysis of the plasmid-encoded hemolysin of Escherichia coli O157: H7 strain EDL 933. Infect Immun 63, 1055-1061. 
Suthienkul, O., Aiumlaor, P., Siripanichgon, K., Eampokalap, B., Likhanonsakul, S.,

Utrarachkij, F. \& Rakue, Y. (2001). Bacterial causes of AIDS-associated diarrhea in Thailand.
Southeast Asian J Trop Med Public Health 32, 158-170.

Vaz, T. M. I., Irino, K., Kato, M. A. M. F., Dias,

A. M. G., Gomes, T. A. T., Medeiros, M. I. C.,
Rocha, M. M. M. \& Guth, B. E. C. (2004). Virulence propertiesand characteristics ofShiga toxin-producing Escherichia coli in São Paulo, Brazil, from 1976 through 1999. J Clin Microbiol 42, 903-905. 